\title{
Backwater effect of multiple bridges along Huaihe River, China
}

\section{Hao Wang MSc}

PhD Student, State Key Laboratory of Hydrology-Water Resources and Hydraulic Engineering, Hohai University, Nanjing, Jiangsu, China Hongwu Tang PhD

Professor, State Key Laboratory of Hydrology-Water Resources and Hydraulic Engineering, Hohai University, Nanjing, Jiangsu, China (corresponding author: hwtang@hhu.edu.cn)

\section{Xinhua Xu MSc}

Senior Engineer, Huaihe River Commission of the Ministry of Water

Resource, Bengbu, China

\section{Jianfeng Xiao MSC}

Senior Engineer, State Key Laboratory of Hydrology-Water Resources and Hydraulic Engineering, Hohai University, Nanjing, Jiangsu, China; Huaihe River Commission of the Ministry of Water Resource, Bengbu, China

\section{Dongfang Liang PhD}

Lecturer, Department of Engineering, University of Cambridge, Cambridge, UK

This study investigated the backwater effect of the eight bridges along the Huaihe River in China using physical model experiments. The experimental data obtained were used to derive equations to parameterise the backwater effect of a single bridge. The cumulative effect of two bridges was then analysed, using the backwater effect of a single bridge as a reference. It was found that, in order to eliminate the cumulative effect, the minimum distance between two bridges should be no less than 215 times the bridge pier width.

\section{Notation}

$B \quad$ width of flow

$B_{1} \quad$ width of main channel

$B_{2} \quad$ width of compound channel

$D \quad$ bridge pier width

$H \quad$ water depth without bridge effect

$h \quad$ afflux

$K_{\theta}, K_{\mathrm{S}} \quad$ coefficients expressing pier alignment and shape

$L \quad$ distance between two bridges

$L_{1} \quad$ length of river reach with increased water depth

$L_{2} \quad$ length of river reach with decreased water depth

$m_{1} \quad$ coefficient depending on the distance between two bridges at a certain $U / U_{\mathrm{f}}$

$Q \quad$ flow discharge

$S_{\mathrm{e}} \quad$ slope of energy line

$S_{0} \quad$ slope of channel bed

$U \quad$ average flow velocity

$U_{\mathrm{f}} \quad$ average flow velocity for bankfull discharge

$\lambda$ blockage ratio (ratio of the area of the piers to the cross-sectional area of flow)

$\lambda_{L} \quad$ horizontal model scale

$\lambda_{Q} \quad$ discharge model scale

\section{Introduction}

Bridges act as an obstruction against river flow, resulting in alteration of the flow characteristics and a change in the original geometry of the nearby river bed. In subcritical flow, one typical kind of flow alteration caused by bridges is the backwater phenomenon, which results in an increase in the water surface level upstream and a reduction downstream of the bridge; a wide longitudinal extent of the river reach is also affected. The interaction between bridge obstruction and river flow increases flooding risks and thus the probability of bridge damage, traffic disruption, loss of human life and economic losses. Researching the influence of bridges on flood control is therefore of critical importance.

The variation in the water surface level and the extent of the backwater-affected river reach are highly dependent on the river section, bridge geometry and characteristics of the flow and the floodplain (Luigia and Kebede, 2013). Many methods for investigating the backwater at bridge crossing sections have been developed. Yarnell (1934) developed the most widely used empirical equation for calculating the increase in water level caused by bridge piers. In that study, 2600 experiments were carried out considering the influence of several parameters on the afflux, including the shape of the piers, the width, the length, the angle and the flow rate. However, Yarnell (1934) did not compare the equation developed with the large amount of data collected through the experiments. Moreover, Yarnell's experiments involved a relatively small percentage of circular columns, which are now a commonly used pier shape. Through experimental studies using a large physical model, Charbeneau and Holley (2001) developed a new equation including a further two parameters as a modification of the equation proposed by Yarnell (1934). Suribabu et al. (2011) also suggested a modified equation, including one more parameter. Regrettably, neither of these two modifications gave a clear physical explanation of the newly added parameters in the equations. Charbeneau and Holley (2001) also reported that the length of the two-dimensional mound of water 
immediately upstream of a bridge pier is no greater than the channel width.

Biery and Delleur (1962) developed a method for the prediction of the afflux at bridges based on laboratory studies using rectangular channels. However, it was found this method could lead to errors when applied to compound channels (Atabay et al., 2008a, 2008b). Many other laboratory and field studies (Kaatz and James, 1997; Seckin, 2004; Seckin et al., 1998) have shown that the energy equation used by the bridge subroutine in HEC-RAS (Hydrologic Engineering Center River Analysis System) (HEC, 2002) is capable of producing accurate estimates of water surface levels in river reaches constricted by bridges. However, considerable inaccuracies may arise in its application depending on the parameters chosen by the user (Seckin et al., 2007). Raju et al. (1983) used experiments to investigate the effect of blockages on the drag coefficient of circular cylinders and obtained a relationship between the energy loss, afflux and drag force. Seckin et al. (2009a, 2009b) applied artificial neural network techniques to derive a regression-based formula for estimating bridge backwater based on laboratory and field data.

In many countries, rapid economic development has led to a sharp increase in traffic volume, thus requiring the construction of additional bridges across rivers and canals. Such construction could cause interactions with existing bridges and affect the characteristics of river flow and sediment motion (Wang et al., 2016a, 2016b). Most of the studies cited above considered single bridges or piers, and little research considering the backwater of a group of bridges has been reported.

In the study reported here, a large physical model of the Huaihe River in China was constructed in order to investigate the effect of a group of bridges on backwater by measuring the water surface level along the plane of symmetry of piers located in the main channel. The data obtained from this study were applied to investigate two specific phenomena: (a) the effect of a single bridge and $(b)$ the cumulative effect of a group of bridges on the backwater of the Huaihe River.

\section{Experimental procedure}

\subsection{Experimental setup}

The physical model, concerning a $22 \mathrm{~km}$ long reach of the Huaihe River from Bengbu sluice to Xinjiawan (Figure 1), was constructed in the State Key Laboratory of Hydrology-Water Resources and Hydraulic Engineering, Hohai University, China. The physical model is $50 \mathrm{~m}$ long and $4 \mathrm{~m}$ wide. The main model scales are shown in Table 1 . The eight bridges along the river reach, in order from upstream, are Daqing Bridge (DQB), Chaoyang Bridge (CYB), K831 Old Bridge (K831OB), K831 New Bridge (K831NB), Jiefang Bridge (JFB), Tielu Bridge (TLB), Jinghu Bridge (JHB) and Changhuaiwei Bridge (CWB) (Figure 1(a)). K831OB and
K831NB are also named the K831 Twin Bridges (K831TB) because of the similar characteristics and the extremely small distance $(25 \mathrm{~m})$ between them. This reach of the Huaihe River was selected because of the dense distribution of bridges and the large possibility of their interaction.

Prototypical landform data of the reach surveyed in 2013 were used to build the physical model. Since there is only one hydrometric station established along this reach, the Huaihe River Commission of the Ministry of Water Resource (HRCMoWR), in cooperation with Hohai University, measured the elevation of the water surface at ten temporary stations along this reach in 2014, as shown in Figure 1(a). The measured data were used to verify the reliability of the physical model. As the maximum discharge in 2014 was less than the bankfull discharge (BFD), differences between the landform of this reach in 2014 and 2013 could be ignored and the reliability of the physical model was verified using the water depths of this reach of the Huaihe River in 2014.

To represent various typical flows of the river, eight different model discharges $(7 \cdot 34,8 \cdot 70,10 \cdot 06,11 \cdot 46,17 \cdot 47,26 \cdot 20,34 \cdot 94$ and $45.42 \mathrm{l} / \mathrm{s}$ ) were used in the experiment. Using the discharge scale $\lambda_{Q}$ shown in Table 1 , the corresponding prototype discharges were 2100, 2490, 2880, 3280, 5000, 7520, 10000 and $13000 \mathrm{~m}^{3} / \mathrm{s}$ respectively. In this river reach, $3280 \mathrm{~m}^{3} / \mathrm{s}$ is the BFD rate and $13000 \mathrm{~m}^{3} / \mathrm{s}$ is the discharge rate of a 100 -year flood, which is the maximum discharge rate the bridges are designed against. The flow discharges were defined by a triangular weir and the experiments were performed under steady flow conditions. The model flow velocity range was $5 \cdot 46-27 \cdot 29 \mathrm{~cm} / \mathrm{s}$.

A comparison of the experimental and surveyed water surface elevations along the Huaihe River is shown in Figure 2. It can be seen that the experimental elevations of the water surface were slightly less than the surveyed values; this is attributable to the concrete floor of the physical model having a smaller roughness than the real river. Fortunately, the difference between the experimental water surface elevation and that of the real river was small and their variation tendencies were similar. Therefore, it was considered reasonable not to increase the roughness of the main channel in the physical model. Although effort was committed to minimising the differences between the model and the natural river, the Reynolds numbers were orders of magnitude larger in the real river because of the model scales.

\subsection{Measurement of the backwater profile of the bridges}

The water surface elevations along the plane of symmetry of piers located in the main channel were measured when the bridges were present in the physical model. The water level was measured by hook gauges of $0 \cdot 1 \mathrm{~mm}$ precision. Measurements were made from $1 \mathrm{~m}$ upstream to $1 \mathrm{~m}$ downstream of the 


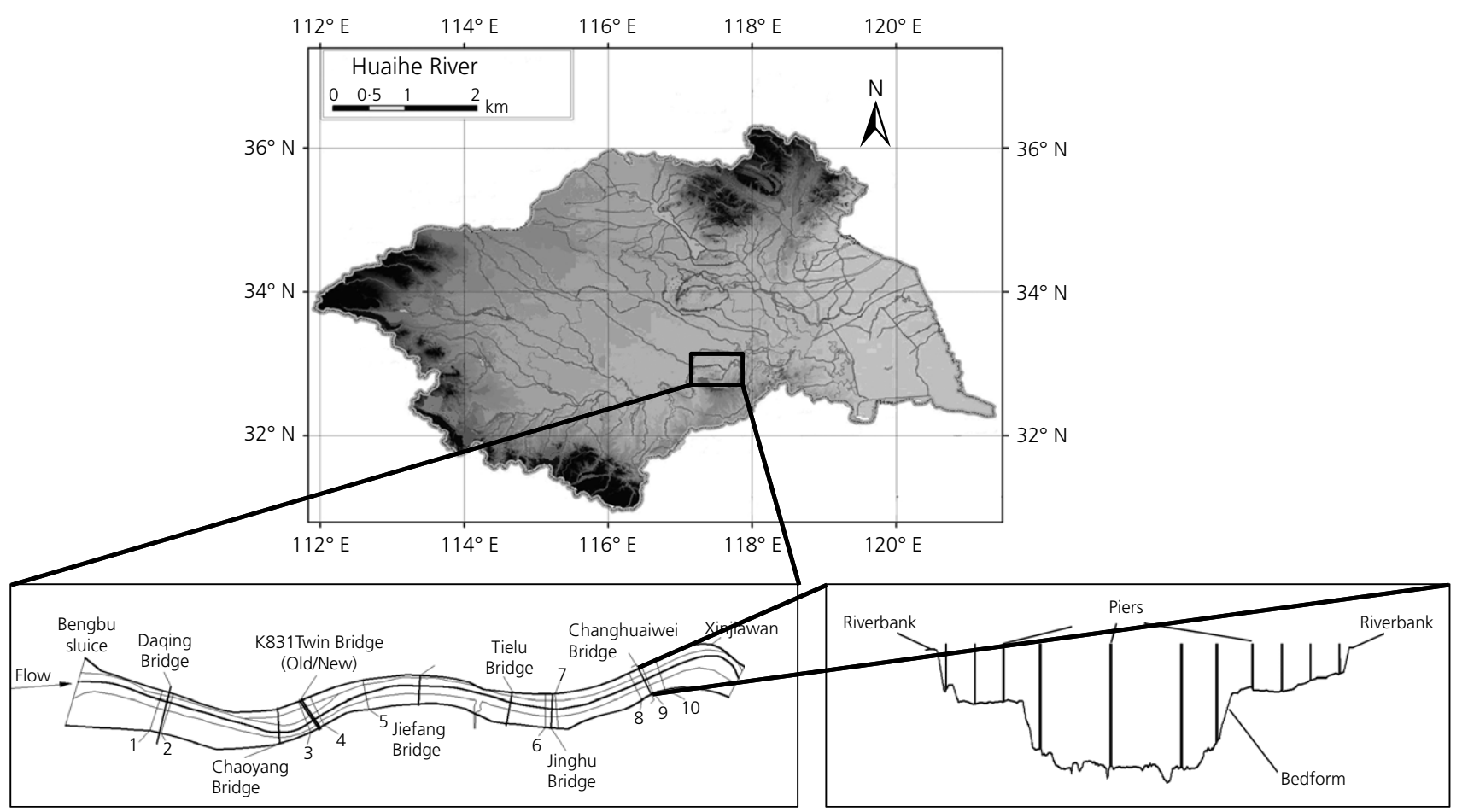

(a)

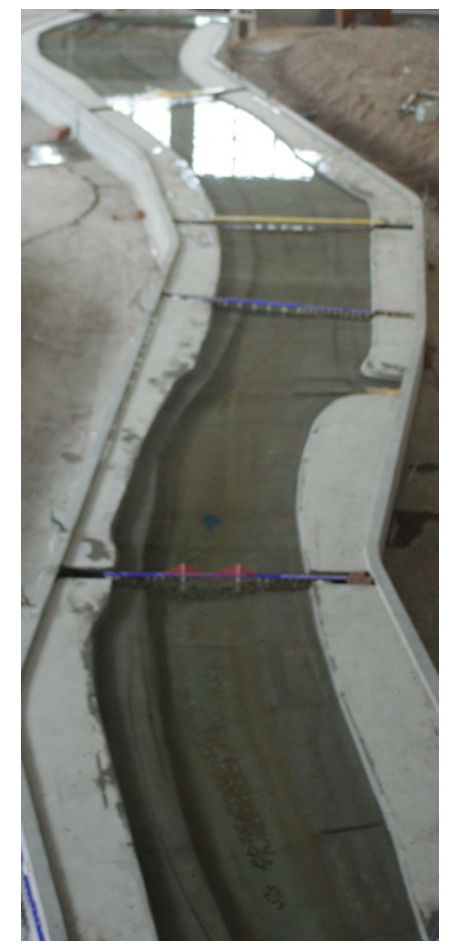

(b)

Figure 1. The Huaihe River reach from Bengbu sluice to

Xinjiawan: (a) location of the study area and test sites (1-10);

(b) the physical model 


\begin{tabular}{lcl} 
Scale name & Model scale & Remarks \\
\hline Horizontal scale, $\lambda_{L}$ & 400 & Determined according to site conditions and test requirement \\
Vertical scale, $\lambda_{H}$ & 80 & Determined based on geometry deformation limit condition \\
Geometry deformation, $D_{t}$ & 5 & $D_{t}=\lambda_{L} / \lambda_{H}$ \\
Discharge scale, $\lambda_{Q}$ & $286216 \cdot 70$ & $\lambda_{Q}=\lambda_{L} \lambda_{H}^{3 / 2}$ \\
Velocity scale, $\lambda_{V}$ & 8.94 & $\lambda_{V}=\lambda_{H}^{1 / 2}$
\end{tabular}

Table 1. Main model scales

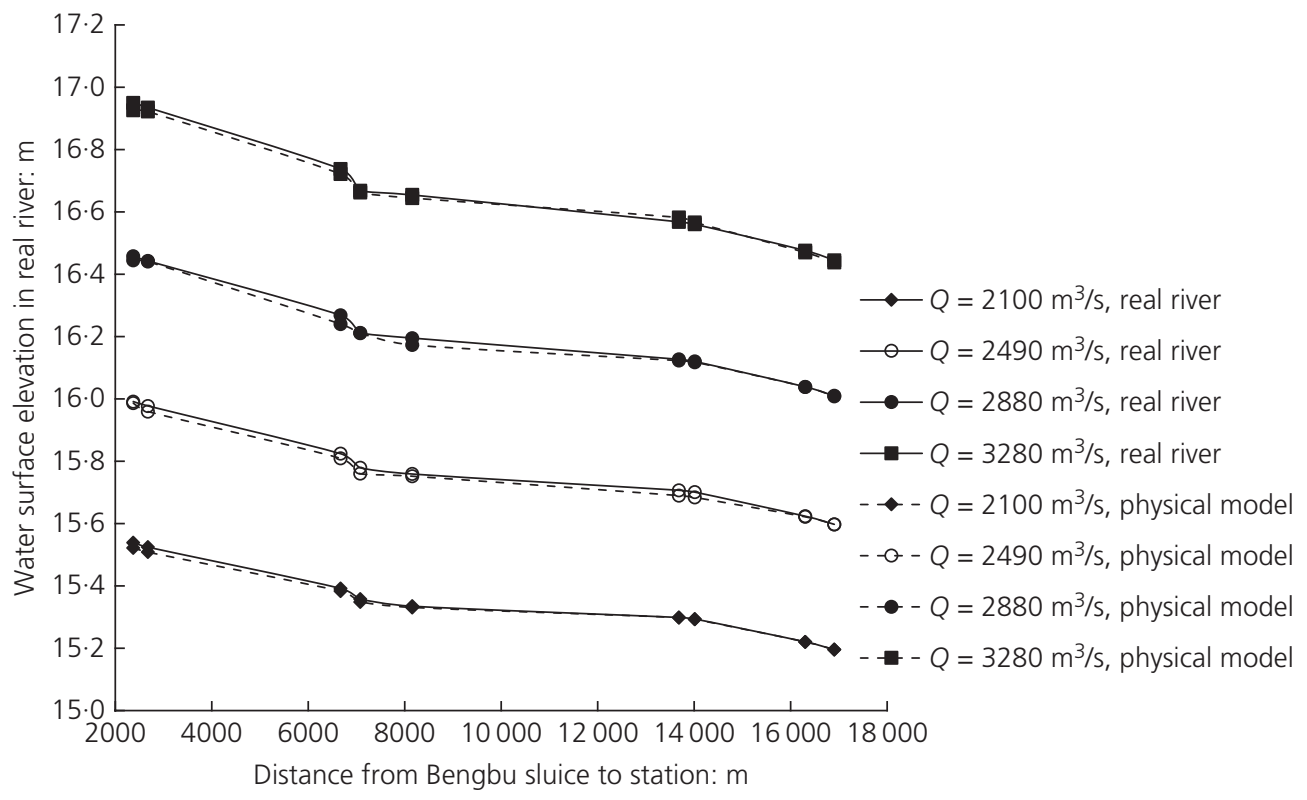

Figure 2. Comparison of the water surface elevation between the real river and the physical model

target pier at $1 \mathrm{~cm}$ intervals, as shown in Figure 3. During the experiments, the model bridges could be removed from the physical model so that the water surface elevations could be measured without them, using the same measuring points as when the bridges were present. Because of the limitation imposed by the decks of the model bridges, the beginning of both the downstream and upstream measuring points was set $3 \mathrm{~cm}$ from the piers. The pier widths of the model bridges were in the range $0.9-1.5 \mathrm{~cm}$, according to the horizontal scale $\lambda_{L}$.

\section{Dimensional analysis}

In engineering applications, focus is mainly on the parameters of the backwater profiles of bridges - that is, the afflux $(h)$, the length of the river reach with increased water depth $\left(L_{1}\right)$ and the length of the reach with decreased water depth $\left(L_{2}\right)$, as shown in Figure 3. Dimensional analysis for the afflux is explored in this section, which is not only used to derive empirical formulas but also to discuss the influence of dimensionless groups on the parameters of the backwater of bridges. The afflux can be described by the following set of independent variables

1.

$$
\begin{aligned}
h=f & {\left[\text { flow }\left(Q, B, H, S_{\mathrm{e}}\right), \operatorname{pier}\left(D, K_{\theta}, K_{\mathrm{S}}, \lambda\right),\right.} \\
& \text { channel } \left.\left(B_{1}, B_{2}, S_{0}\right)\right]
\end{aligned}
$$

where $Q$ is the discharge, $B$ is the width of flow, $H$ is the water depth without the bridge where increased depth occurs, $S_{\mathrm{e}}$ is the slope of the energy line, $D$ is the pier width, $K_{\theta}$ and $K_{\mathrm{S}}$ are coefficients expressing the pier alignment and shape, respectively, $\lambda$ is the blockage ratio (ratio of the area of the piers to the cross-sectional area of the flow), $B_{1}$ is the width of the main channel, $B_{2}$ is the width of the compound channel and $S_{0}$ is the slope of the channel bed.

Generally, $S_{\mathrm{e}}$ and $S_{0}$ are determinants of the water surface elevation along a real river. For the Huaihe River reach 


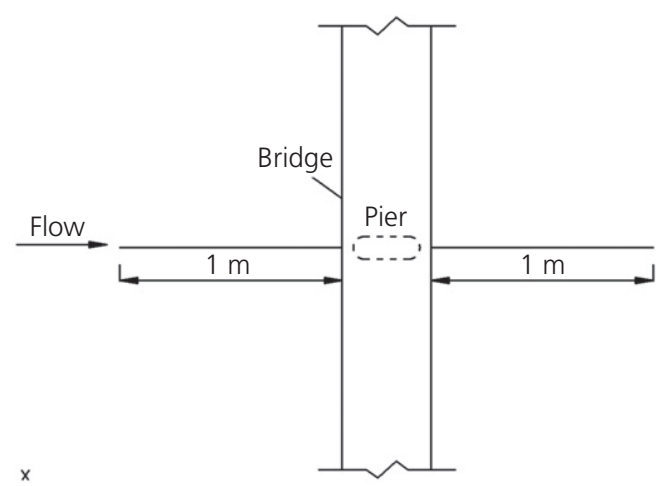

(a)

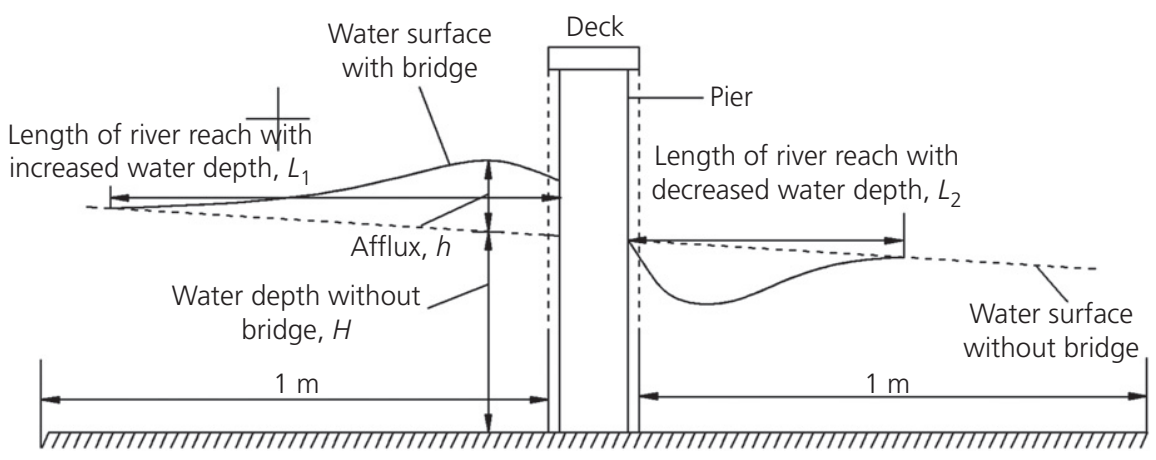

(b)

Figure 3. Measurement of the backwater of the bridges:

(a) plane view; (b) side view

involved in this study - an alluvial river reach of $22 \mathrm{~km}$ length - the change of water surface elevation caused by the slopes is slight in subcritical conditions. Consequently, it could be assumed that $S_{\mathrm{e}}$ and $S_{0}$ have little influence on the afflux and thus they are ignored during the following analysis. Therefore, here, the afflux considers the difference resulting from the obstacle of the piers rather than the slope of the channel bed.

Considering the horizontal scale effects $\left(\lambda_{L}\right)$, the shapes of the piers were unified as round-nosed, as their model sizes were so small that their exiguous differences could hardly influence the physical process; it was also difficult to express pier shape in the model. The HRC-MoWR rules that the skew angle of the flow direction resulting from pier alignment should be less than $10^{\circ}$; therefore, it was considered that pier alignment had little influence on the afflux and thus $K_{\theta}$ and $K_{\mathrm{S}}$ were also not investigated in this study.

In a compound channel river, the variables $H, B$ and $B_{1}$ are applied to express the complexity of the cross-sectional shape of the channel and the average flow velocity $U$ is used in place of the discharge to express the flow characteristics. The blockage ratio $\lambda$ is used to express obstruction to flow caused by the piers of a single bridge, especially for high velocities. Generally, a larger value of $\lambda$ represents a more obvious obstruction. The cumulative effect of the piers of a single bridge can be expressed by the blockage ratio $\lambda$. With the assumptions stated above, Equation 1 can be transformed into

2. $\frac{h}{D}=f\left(\frac{U}{U_{\mathrm{f}}}, \frac{B}{H}, \frac{B}{B_{1}}, \lambda\right)$

where $U_{\mathrm{f}}$ is the average flow velocity for BFD.

The experiments reported here were designed to contribute to the definition of Equation 2 and, ultimately, to evaluate the cumulative effects of a group of bridges, based on Equation 2 .

\section{Results and discussion}

\subsection{Change in water surface due to a single bridge} Firstly, only a single bridge was placed in the physical model each time. Then, the differential curves of the water surface with a single bridge and with no bridge were obtained, as shown in Figure 4 (the positive/negative value of the $x$-axis denotes upstream/downstream of the bridge). Figure 4 illustrates the differential curve of bridge DQB as an example, but the curves of the other bridges were similar. The values of $h$, $L_{1}$ and $L_{2}$ can be obtained from Figure 4. It can be seen that, as the discharge increases, these parameters increase as 


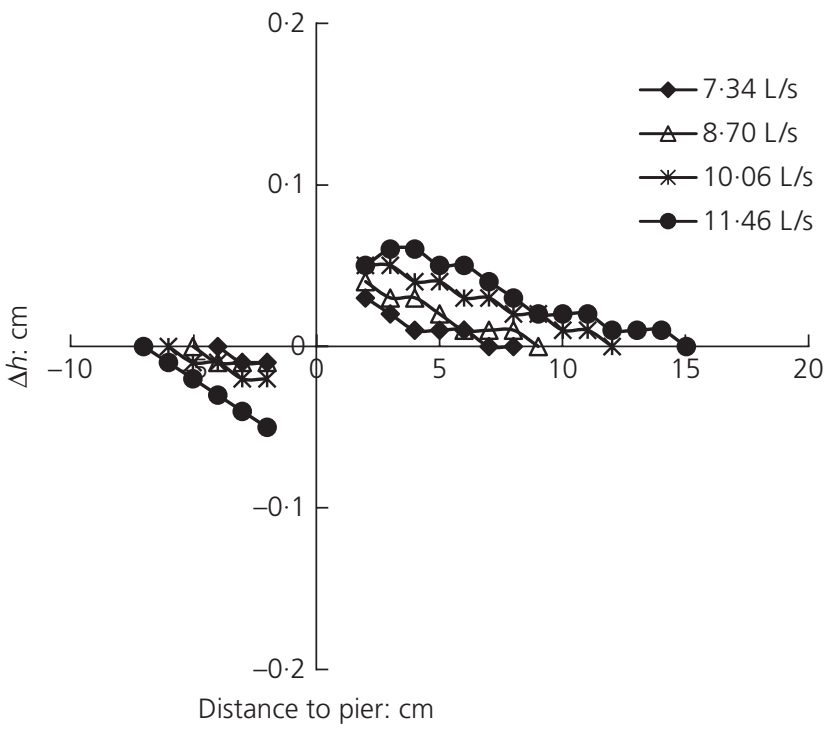

(a)

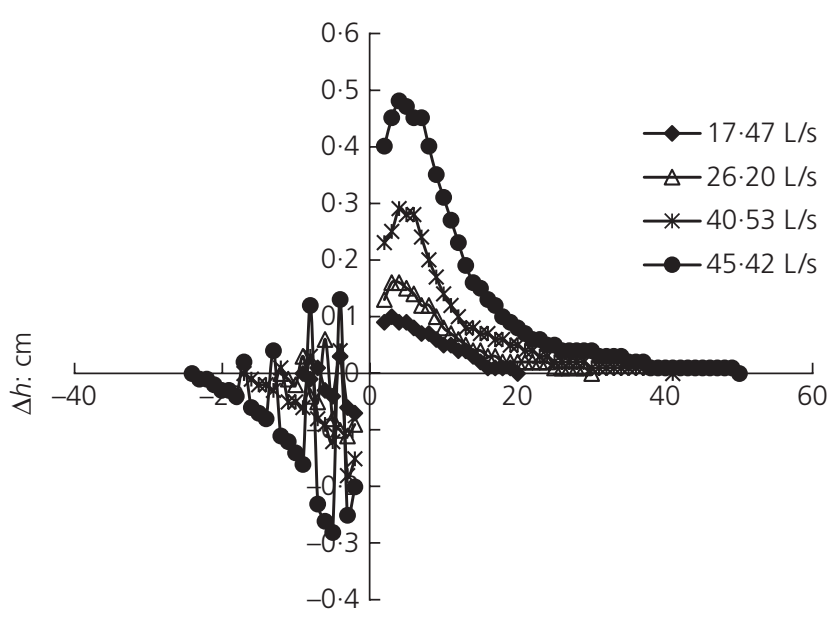

Distance to pier: $\mathrm{cm}$

(b)

Figure 4. Differential curves of water surface between a single bridge (DQB) and no bridge: (a) discharges less than the BFD;

(b) discharges exceeding the BFD

well. For each discharge less than the BFD (Figure 4(a)), the curve of the reach with decreased water depth decreases monotonically, but when the discharge exceeds the BFD, the curve of the reach with decreased water depth fluctuates. Because this phenomenon does not exist for discharges less than BFD and the gradient change of the differential curve for discharges less than BFD is much smaller than for discharges that exceed $\mathrm{BFD}$, the following analysis is divided into two parts discharges less than BFD and discharges that exceed BFD.

\subsection{Afflux of a single bridge}

The relationship between $h / \mathrm{D}$ and $U / U_{\mathrm{f}}$ is shown in Figure 5 for discharges less than the BFD. It was found that this

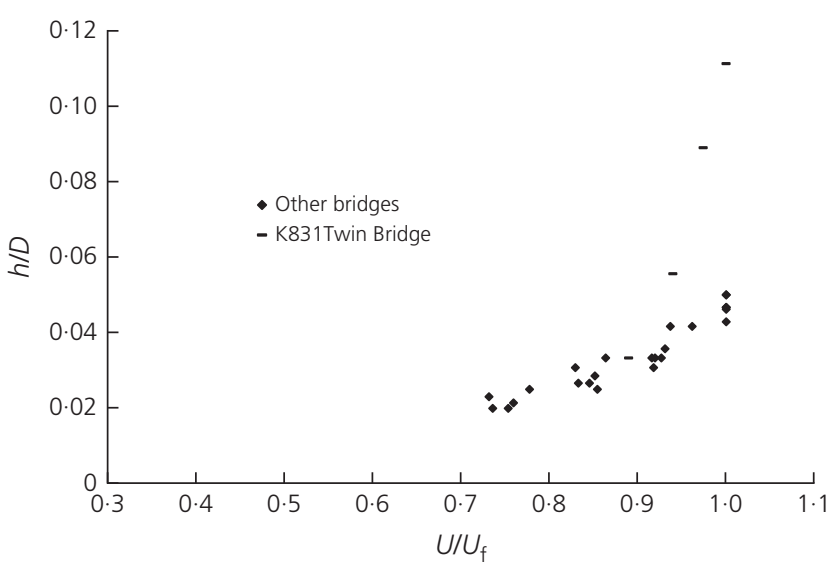

Figure 5. Afflux for discharges less than the BFD

relationship was similar for all the studied bridges, except for K831TB. Analysis of the landform of the Huaihe River revealed that the cross-sectional area of the main channel at K831TB was smaller than for the other bridges and thus the smallest discharge adopted in the experiment constituted an overbank flow in this section. Therefore, all the data for $\mathrm{K} 831 \mathrm{~TB}$ were treated as discharges exceeding the BFD.

To describe the relationship between $h / \mathrm{D}$ and $U / U_{\mathrm{f}}$ empirically, the following best-fit function was developed

3. $\frac{h}{D}=0.00105 \mathrm{e}^{3.95 U / U_{\mathrm{f}}}\left(\frac{B}{H}\right)^{0.05}$

as shown in Figure 6.

Equation 3 does not contain $\lambda$ because it is too small (i.e. $<6 \%$ ) to have a significant influence on the afflux $h$ when $U / U_{\mathrm{f}}$ is small.

Figure 7 shows the relationship between $h / \mathrm{D}$ and $U / U_{\mathrm{f}}$ for discharges that exceed the BFD, which indicates that $h / \mathrm{D}$ increases exponentially with $U / U_{\mathrm{f}}$ for each bridge. Because the shape of the cross-section of the flow is different for each bridge and the interaction between piers is obvious as the discharge increases, the curves of $h / \mathrm{D}$ and $U / U_{\mathrm{f}}$ for each bridge are dissimilar. Considering the above analysis, the experimental data were substituted into Equation 2 and the following relationship was obtained

4. $\frac{h}{D}=0.0851 \mathrm{e}^{1.464 U / U_{\mathrm{f}}}\left(\frac{B}{\left(B_{1} H\right)^{0.5}}\right)^{2 \cdot 2}(100 \lambda)^{0.027}$

Equation 4 considers the impact of the blockage coefficient $\lambda$ on the afflux, based on the following: $(a)$ when the discharge exceeds the BFD, the blockage coefficient will increase (up to 


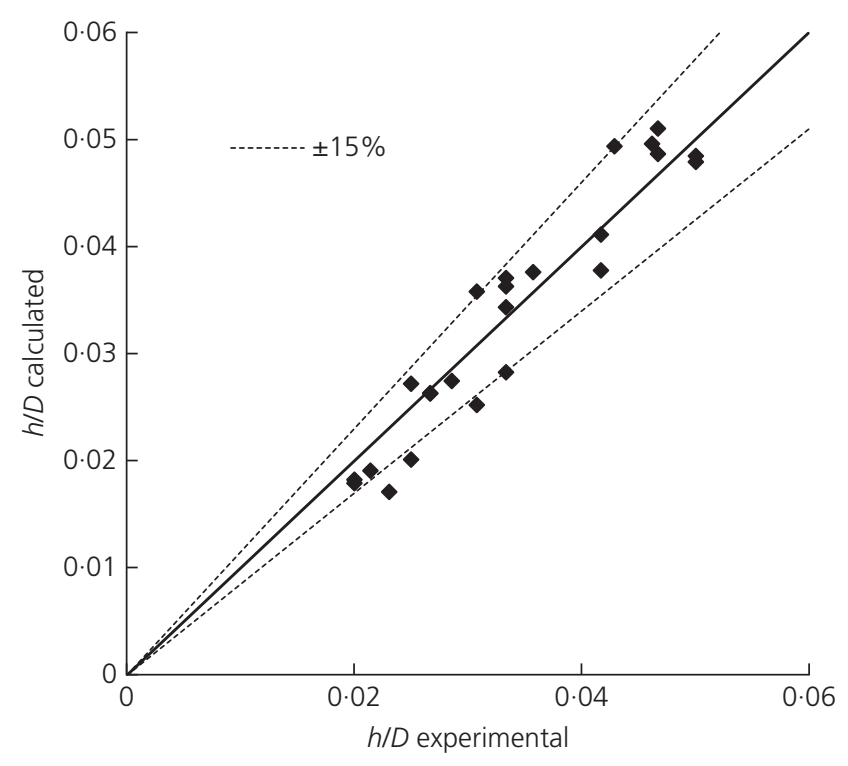

Figure 6. Comparison of experimental and calculated afflux for discharges less than the BFD

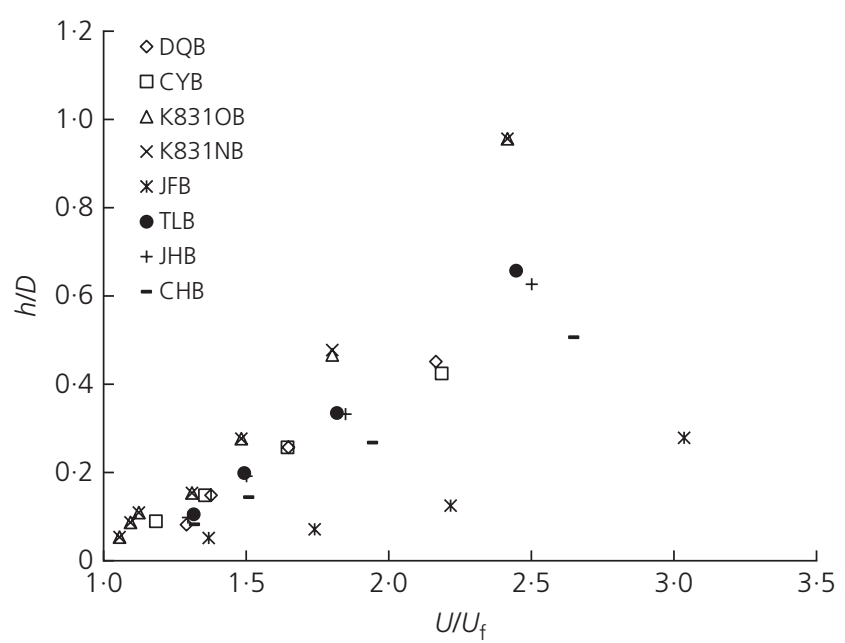

Figure 7. Afflux for discharges exceeding the BFD

$9 \cdot 11 \%$ ) as piers located in the floodplain will also obstruct the flow; $(b)$ as the velocity increases, the interaction among piers in a transverse arrangement becomes more obvious. Figure 8 shows the relationship between the observed $h / \mathrm{D}$ values and those computed using Equation 4.

\subsection{Length of the reach with increased water depth and with decreased water depth}

Based on the experimental data, it was found that the length of the river reach with increased water depth $\left(L_{1}\right)$ and the length of the river reach with decreased water depth $\left(L_{2}\right)$

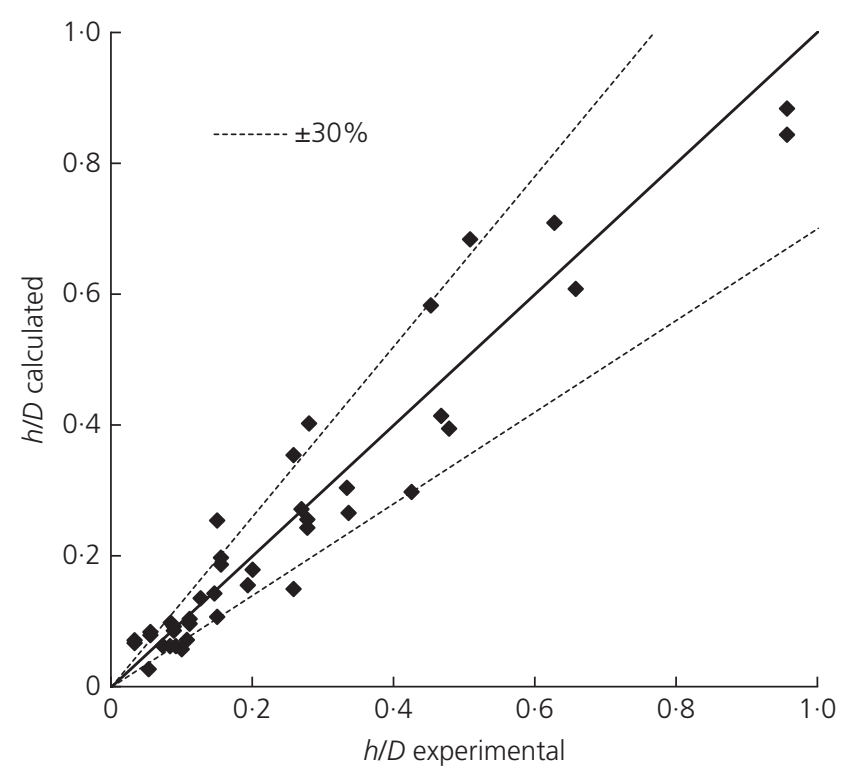

Figure 8. Comparison of experimental and calculated values for discharges exceeding the BFD

increase linearly with $h / \mathrm{D}$; the equations can thus be expressed as

5. $\frac{L_{1}}{D}=281 \cdot 76 \frac{h}{D}$

6. $\frac{L_{2}}{D}=167 \cdot 12 \frac{h}{D}$

as shown in Figures 9 and 10, respectively.

Here, $L_{1} / \mathrm{D}, L_{2} / \mathrm{D}$ and $h / \mathrm{D}$ conform to an exponential relationship and the equations can be expressed as

7. $\frac{h}{D}=0.0239 \mathrm{e}^{0.0624 L_{1} / d}$

8. $\frac{h}{D}=0.0385 \mathrm{e}^{0.01096 L_{2} / d}$

as shown in Figures 11 and 12, respectively.

The correlation between $L_{2} / \mathrm{D}$ and $h / \mathrm{D}$ is not strong. However, in engineering applications, the focus tends to be mainly on the maximum possible value of $L_{2}$ for the decreased water depth, therefore Equation 8 represents an envelope that can be considered reasonable. 


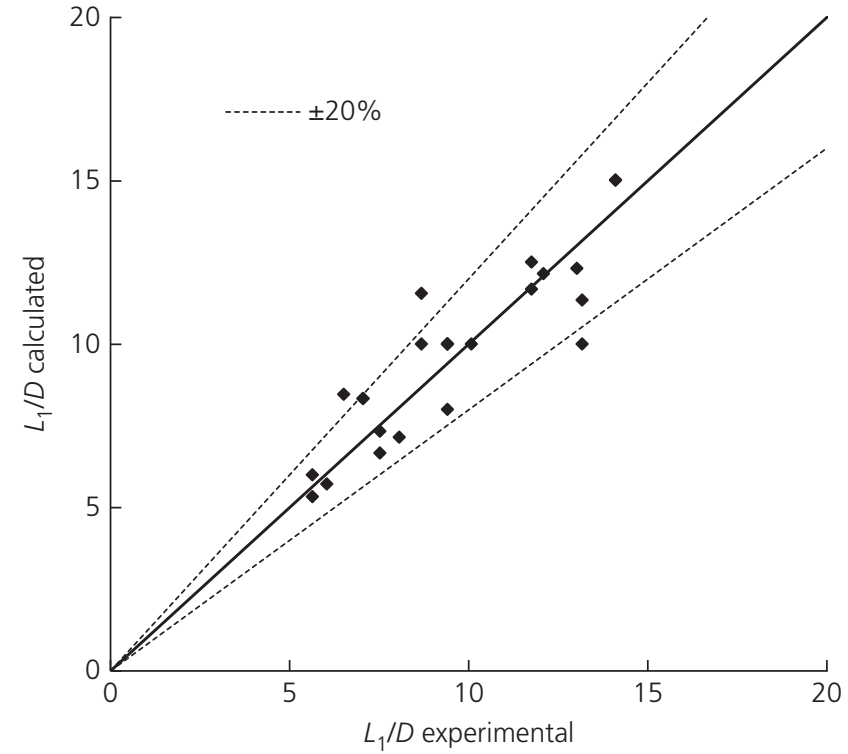

Figure 9. Comparison of experimental and calculated $L_{1} / D$ for discharges less than the BFD

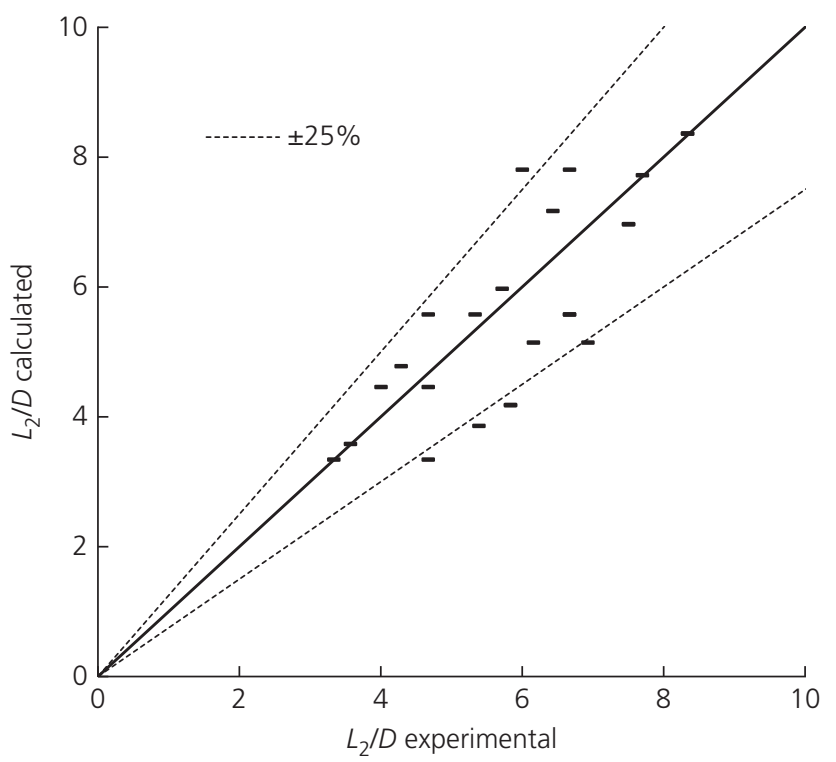

Figure 10. Comparison of experimental and calculated $L_{2} / D$ for discharges less than the BFD

Obviously, the backwater characteristics of a single bridge with discharges less than the BFD are different from those with discharges exceeding the BFD. This may explain why some research conducted in a rectangular channel can lead to inaccuracy when applied to compound channels.

\subsection{Cumulative effect of two bridges on backwater} Based on the analysis of the backwater of a single bridge, the cumulative effect of two bridges on backwater was investigated

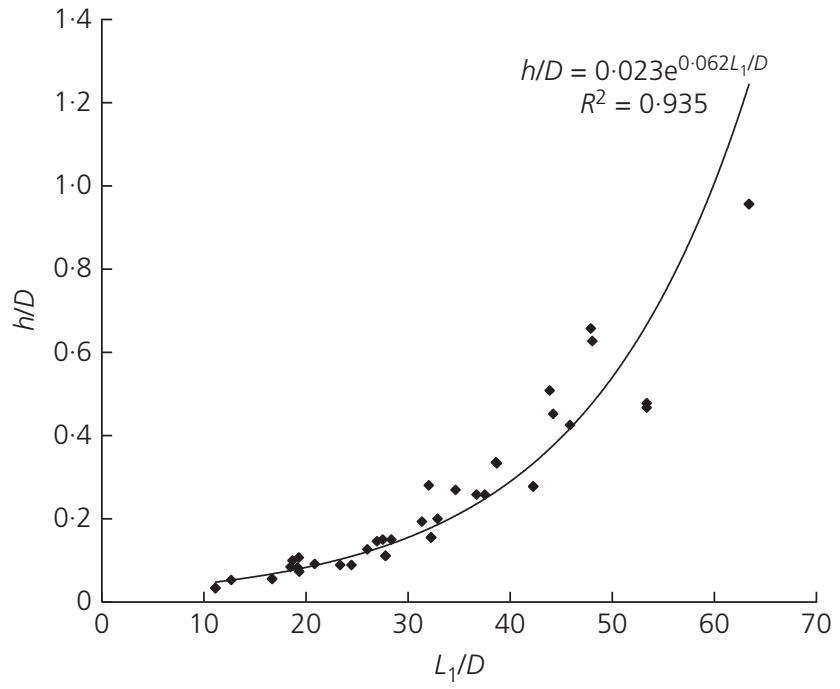

Figure 11. Relationship between $h / D$ and $L_{1} / D$ for discharges exceeding the BFD

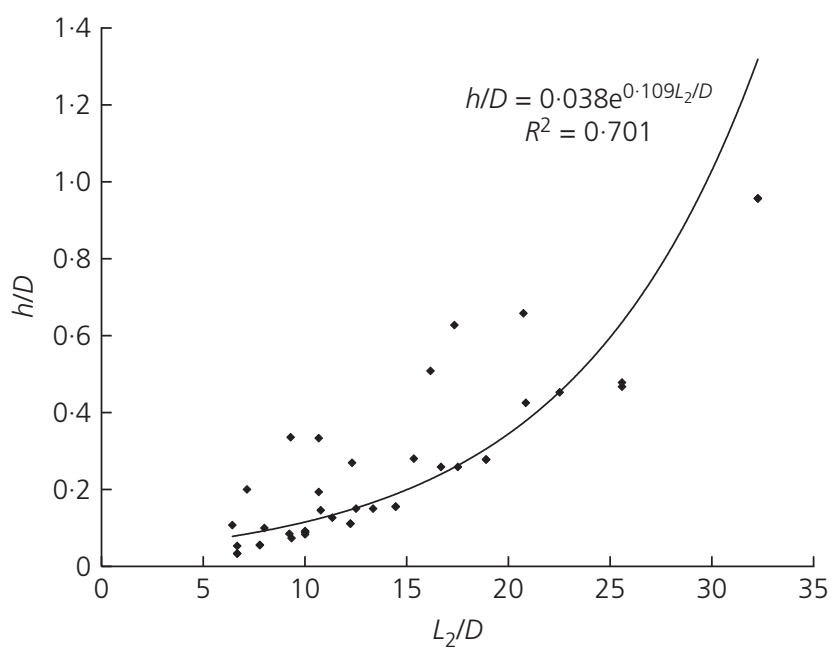

Figure 12. Relationship between $h / D$ and $L_{2} / D$ for discharges exceeding the BFD

for different combinations of two bridges. Only four cases showed an observable cumulative effect on the backwater of the upstream bridge under certain discharges, as shown in Table 2. For cases 2, 3 and 4, the values of $h, L_{1}$ and $L_{2}$ were the same as those for a single bridge when the discharge was less than $34.94 \mathrm{l} / \mathrm{s}$ (corresponding to $10000 \mathrm{~m}^{3} / \mathrm{s}$ in full scale). When the discharge was increased to $34.941 / \mathrm{s}$, the value of $h$ was larger than that of a single bridge, while $L_{1}$ and $L_{2}$ remained the same. Finally, when the discharge was increased to $45.421 / \mathrm{s}\left(13000 \mathrm{~m}^{3} / \mathrm{s}\right.$ in full scale), the values of $h$ and $L_{1}$ were larger than those of the single bridge, with the value of $L_{2}$ remaining the same. Therefore, it was established that the cumulative effect of two bridges becomes more obvious as 


\begin{tabular}{llccccc} 
Case & Bridges & L/D & Model discharge: I/s & $h$ & $L_{1}$ & $L_{2}$ \\
\hline 1 & K831OB and K831NB & 6.94 & $7 \cdot 34-45 \cdot 42$ & $Y$ & $Y$ & $Y$ \\
2 & CYB and K831OB & 208.33 & 34.94 & $Y$ & $\mathrm{~N}$ & $\mathrm{~N}$ \\
& & 45.42 & $\mathrm{Y}$ & $\mathrm{Y}$ & $\mathrm{N}$ \\
3 & CYB and K831NB & 213.54 & 34.94 & $\mathrm{Y}$ & $\mathrm{N}$ & $\mathrm{N}$ \\
& & 45.42 & $\mathrm{Y}$ & $\mathrm{Y}$ & $\mathrm{N}$ \\
4 & TLB and JHB & 214.28 & 34.94 & $\mathrm{Y}$ & $\mathrm{N}$ & $\mathrm{N}$ \\
& & & 45.42 & $\mathrm{Y}$ & $\mathrm{Y}$ & $\mathrm{N}$
\end{tabular}

Table 2. Cases for which a cumulative effect of two bridges existed (' $Y$ ' means the cumulative effect of two bridges existed; ' $N$ ' means the cumulative effect of two bridges did not exist)

discharge increases and that the cumulative effect is more significant on $h$ and has least effect on $L_{2}$.

A cumulative effect of two bridges on the backwater of the downstream bridge was not found in cases 2, 3 and 4. It is thus considered that the cumulative effect of two bridges is mainly on the upstream bridge. In case $1, \mathrm{~K} 831 \mathrm{OB}$ is so close to $\mathrm{K} 831 \mathrm{NB}$ that it is difficult to distinguish between the $L_{1}$ of $\mathrm{K} 831 \mathrm{NB}$ and the $L_{2}$ of $\mathrm{K} 831 \mathrm{OB}$. Therefore, only $L_{1}$ of K831OB (the upstream bridge) and $L_{2}$ of K831NB (the downstream bridge) were obtained. Figure 13 shows the discrepancy in backwater parameters between K831TB and K831OB (or $\mathrm{K} 831 \mathrm{NB}$, as the values of $\mathrm{K} 831 \mathrm{NB}$ were the same as those of $\mathrm{K} 831 \mathrm{OB}$ under the single-bridge condition). The discrepancy becomes more obvious with an increase in discharge, meaning that the cumulative effect is more obvious as discharge increases. These findings agree with those derived from cases 2, 3 and 4.

The backwater parameters for case 1 can be expressed as

9. $\frac{h_{\mathrm{t}}}{D}=1.45 \frac{h}{D}$

10. $\frac{L_{1 \mathrm{t}}}{D}=1 \cdot 29 \frac{L_{1}}{D}$

11. $\frac{L_{2 \mathrm{t}}}{D}=1 \cdot 26 \frac{L_{2}}{D}$

where the subscript ' $\mathrm{t}$ ' denotes two bridges, as shown in Figure 14. According to the coefficients in Equations 9-11, the cumulative effect on $h$ is the most significant, which agrees with the results for cases 2,3 and 4 .

\subsection{Maximum extent of the cumulative effect}

According to the above findings, the cumulative effect of two bridges increases the backwater parameters compared with a single bridge, which undoubtedly increases the difficulty of flood control. Therefore, determination of the maximum extent of the cumulative effect is obviously important for field engineering practice.

The conclusions in Section 4.4 reveal that the cumulative effect on the afflux $h$ is the most significant. Therefore, to establish the maximum extent of the cumulative effect, all that is needed is to determine the threshold distance between the two bridges for which the value of $h$ no longer changes (i.e. the same as single-bridge conditions). Since the cumulative effect occurs only when the discharge exceeds the BFD, Equation 4 for a single bridge is taken as a standard to obtain the threshold distance in the following analysis.

Firstly, Equation 4 is transformed into the following form, which describes the relationship between the afflux and flow condition for a single bridge in another way

12. $\frac{h}{D} /\left[\left(\frac{B}{\left(B_{1} H\right)^{0.5}}\right)^{2 \cdot 2}(100 \lambda)^{0.027}\right]=0.0851 \mathrm{e}^{1.464 U / U_{\mathrm{f}}}$

Then, a comprehensive parameter to describe the afflux characteristics of either two bridges or a single bridge is defined as

13. $F(h / D)=\frac{h}{D} /\left[\left(\frac{B}{\left(B_{1} H\right)^{0.5}}\right)^{2 \cdot 2}(100 \lambda)^{0.027}\right]$

To derive the threshold distance between two bridges, the experimental results are illustrated in Figure 15 in terms of the relationship between $F(h / D)$ and $U / U_{\mathrm{f}}$. In the figure, parallel lines are drawn at the maximum experimental values of $U / U_{\mathrm{f}}$ (corresponding to the maximum discharge of $45.42 \mathrm{l} / \mathrm{s}$ (13 $000 \mathrm{~m}^{3} / \mathrm{s}$ in full scale)) for the four cases listed in Table 2 . All the parallels have the same slope with the derivative of 


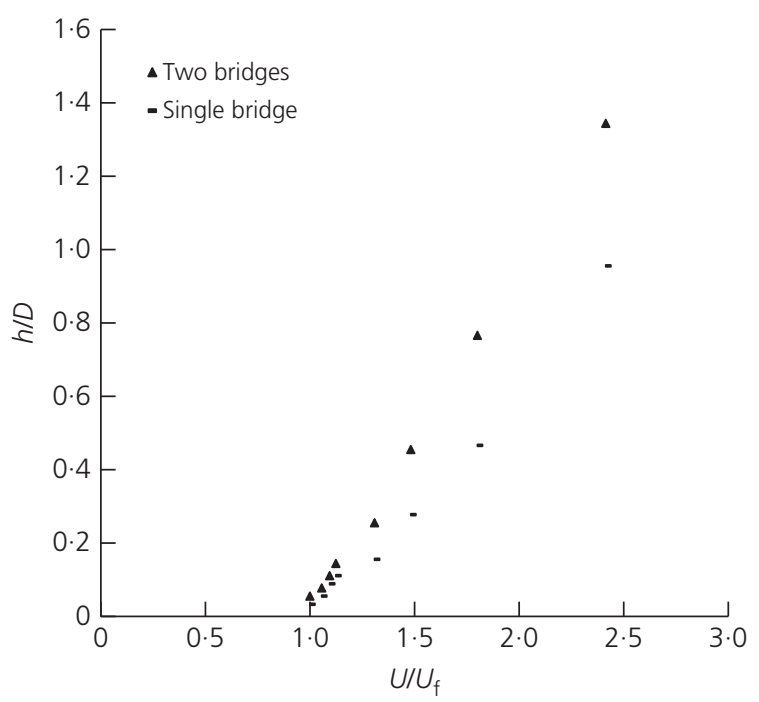

(a)

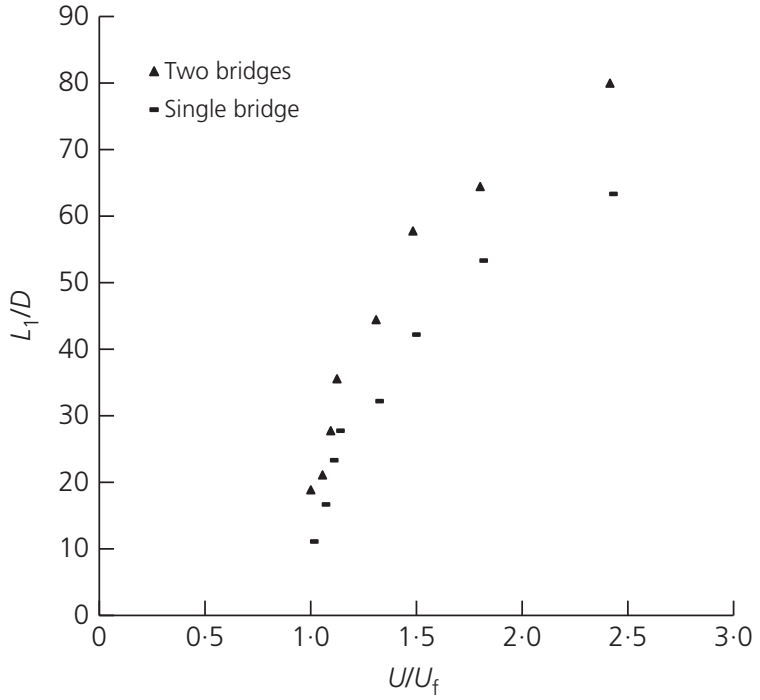

(b)

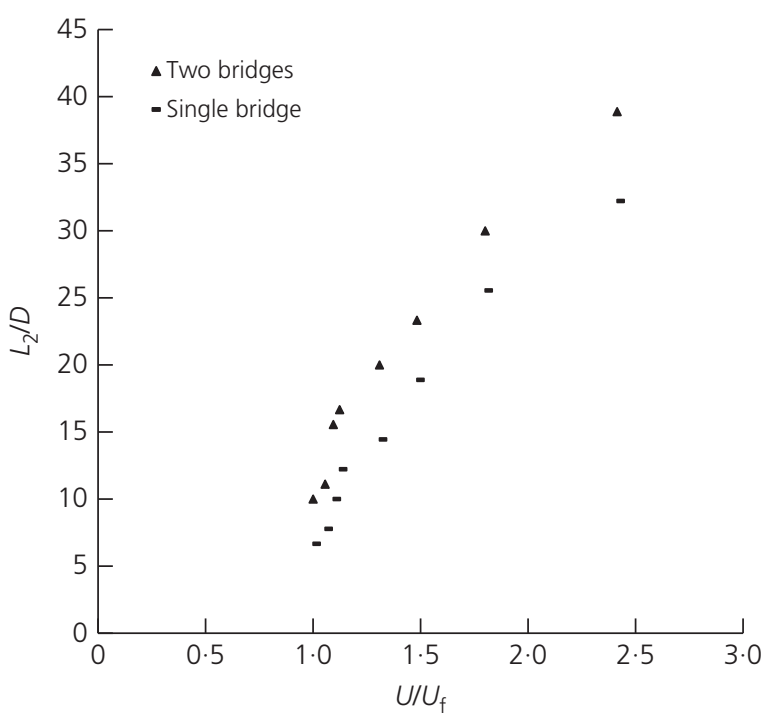

(c)

Figure 13. Discrepancy of backwater parameters between

K831TB and K831OB: (a) $h / D$; (b) $L_{1} / D$; (c) $L_{2} / D$

Equation 12 at the maximum $U / U_{\mathrm{f}}$ (i.e. a single-bridge condition), so that we can obtain the maximum values of $F(h / D)$ for each case corresponding to the maximum $U / U_{\mathrm{f}}$ of the whole reach. Furthermore, the impact of the distance between two bridges $L$ on the afflux was assessed. It was found that the maximum $F(h / D)$ of two bridges became closer to that of a single bridge as $L / \mathrm{D}$ increases, as shown in Figure 15.

Because of the different section shapes, the maximum experimental values of $U / U_{\mathrm{f}}$ for cases 2 and 3 are smaller than those of the whole reach. Thus, the maximum $F(h / D)$ for these two cases would be larger than the actual values under the exponential law, as they were also obtained using the 'parallel method' by extending to the maximum $U / U_{\mathrm{f}}$ of the whole reach. This kind of treatment is safer for engineering applications.

Based on the above analysis, let us assume that

14. $\quad F_{\mathrm{t}}(h / D)=m_{1} F_{\mathrm{a}}(h / D)$

where subscripts ' $t$ ' and ' $a$ ' denote two bridges and a single bridge, respectively, and the coefficient $m_{1}$ depends on the distance between two bridges $(L)$ at a certain $U / U_{\mathrm{f}}$.

When $m_{1}=1$, it means that there is no difference between the two-bridge condition and the single-bridge condition, and 


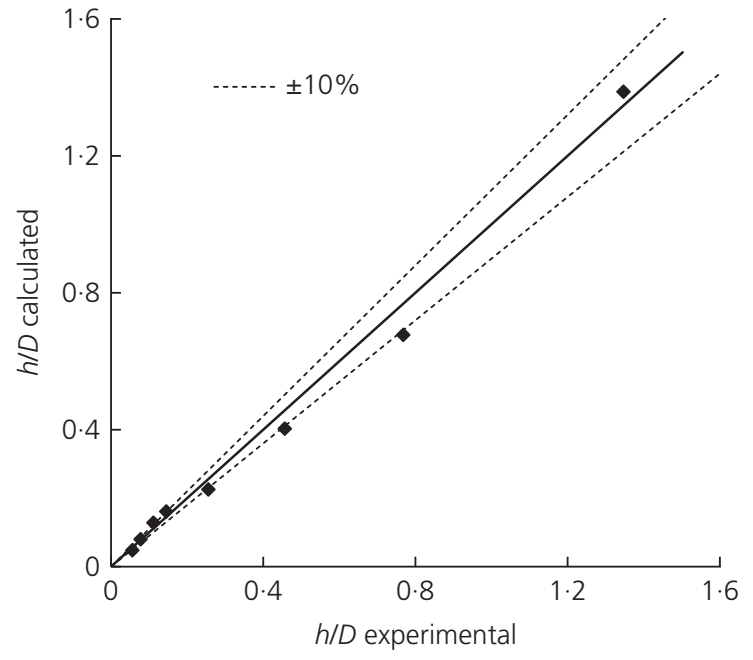

(a)

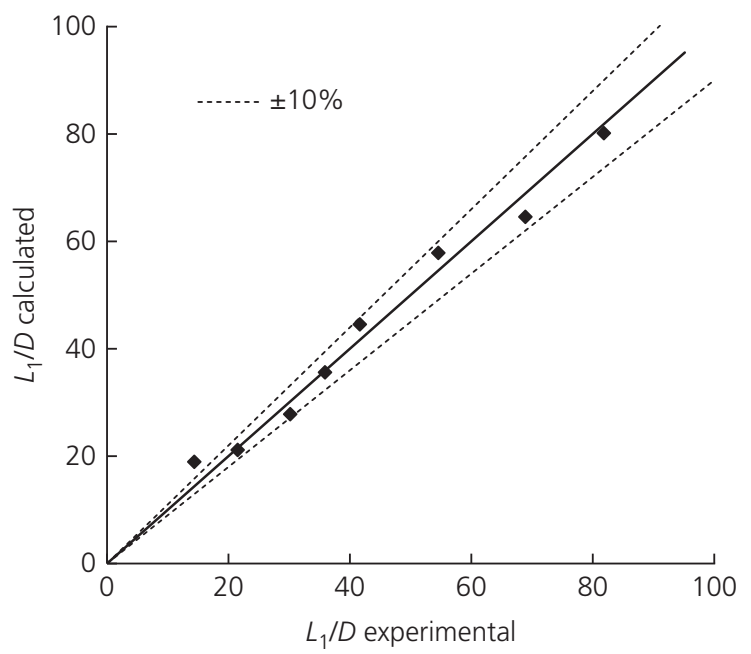

(b)

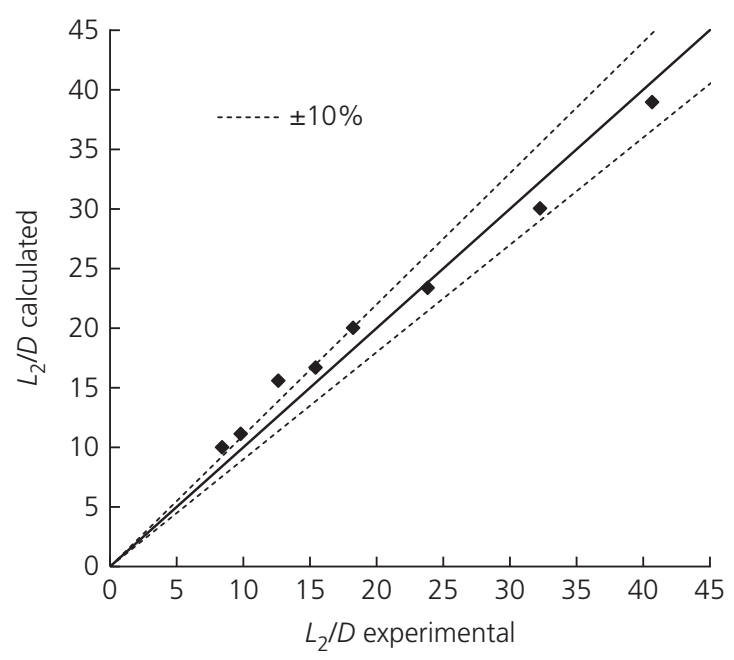

(c)

Figure 14. Comparison of experimental and calculated backwater parameters for K831TB: (a) $h / D$; (b) $L_{1} / D$; (c) $L_{2} / D$

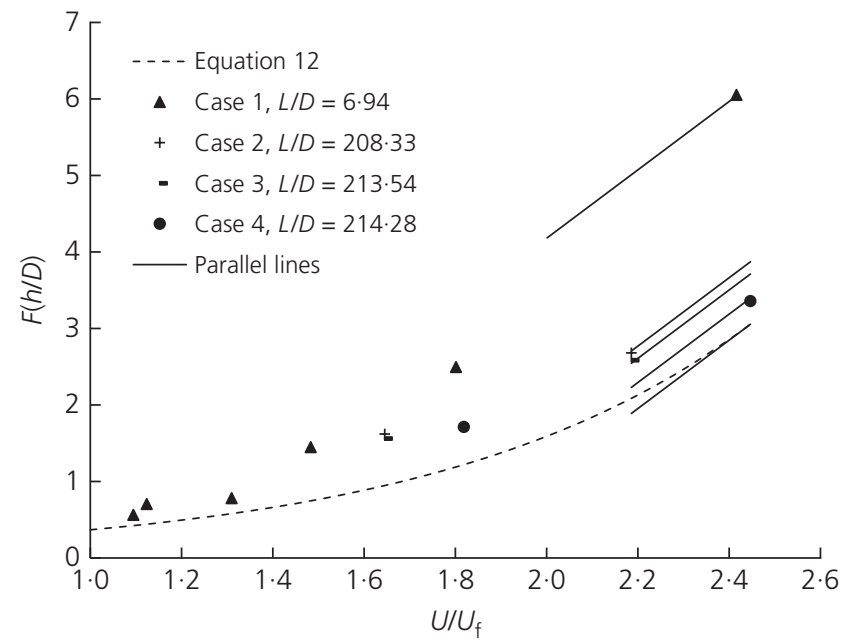

Figure 15. Variation of $F(h / D)$ with $U / U_{f}$

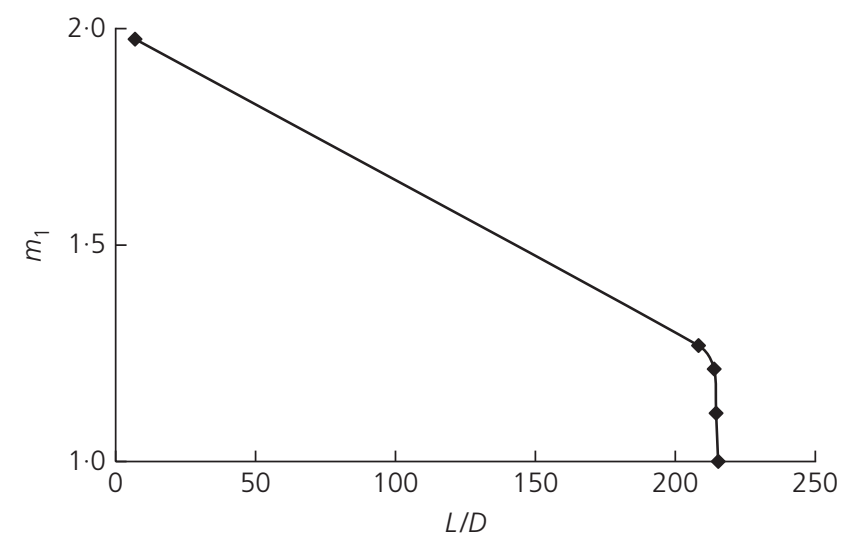

Figure 16. Variation of $m_{1}$ with $L / D$

the corresponding $L$ could be considered as the threshold distance between two bridges at a certain $U / U_{\mathrm{f}}$. Figure 16 shows the relationship between $m_{1}$ and $L / \mathrm{D}$ at the maximum $U / U_{\mathrm{f}}$ of the whole reach. Extending the curve to the $x$-axis $\left(m_{1}=1\right)$ yields $L / D=215$. This means that the cumulative effect disappears when $L / D=215$ and thus this is defined as the maximum extent of the cumulative effect on bridge afflux under two-bridge conditions.

\section{Conclusions}

The following conclusions were drawn from this study of the backwater of a group of bridges on the Huaihe River in China.

(a) When the discharge is less than bankfull discharge (BFD), Equations 3, 5 and 6 can be used to describe the parameters of the backwater of a single bridge. When the 
discharge exceeds the BFD, Equations 4, 7 and 8 describe those parameters.

(b) There is a cumulative effect of two bridges on the backwater for certain discharges and distances. The cumulative effect on the afflux is most obvious and least evident on the length of the reach with decreased water depth.

(c) By analysing discrepancies between the backwater shapes of a single bridge and two bridges, it was established that the value of $L / D=215$ represents the minimum separation between nearby bridges for the cumulative effect to disappear along the studied reach of the Huaihe River.

It is hoped that these experimental results will provide useful guidelines for future bridge construction and embankment maintenance on the Huaihe River. The cumulative effect of hydraulic structures increases the difficulty of flood control in the river, and the present results provide technical support as to how such effects can be avoided.

\section{Acknowledgements}

This work was supported by a Special Fund for Public Welfare of the Water Resources Ministry (grant 201501007), China National Funds for Distinguished Young Scientists (grant 51125034), the National Natural Science Foundation of China (grant 51279046), Fundamental Research Funds for the Central Universities (grant 2014B02714) and Colleges and Universities in Jiangsu Province Plans for Graduate Research and Innovation (grant KYZZ_0146).

\section{REFERENCES}

Atabay S, Knight DW, Seckin N and Seckin G (2008a) Improving bridge afflux prediction for overbank flows. Proceedings of the Institution of Civil Engineers - Water Management 161(5): 253-260, http://dx.doi.org/10.1680/wama.2008.161. 5.253 .

Atabay S, Seckin G, Seckin N and Knight DW (2008b) Effect of the Froude number on assessment of the bridge afflux. Proceedings of the Institution of Civil Engineers - Water Management 161(2): 97-104, http://dx.doi.org/10. 1680/wama.2008.161.2.97.

Biery PF and Delleur JW (1962) Hydraulics of single span arch bridge constrictions. ASCE Journal of Hydraulics $\mathbf{8 8 ( 2 )}$ : 75-108.

Charbeneau RJ and Holley ER (2001) Backwater Effects of Piers in Subcritical Flow. Center for Transportation Research, The University of Texas at Austin, Austin, TX, USA, Report FHWA/TX-0-1805-1.

HEC (Hydrologic Engineering Center) (2002) HEC-RAS River Analysis System. HEC, US Army Corps of Engineers, Davis, CA, USA, Version 3.1, Beta.

Kaatz KJ and James WP (1997) Analysis of alternatives for computing backwater at bridges. Journal of Hydraulic Engineering 123(9): 784-792.
Luigia B and Kebede WM (2013) Uncertainty in the estimation of backwater effects at bridge crossings. Hydrological Processes 27(9): 1292-1300.

Raju KGR, Rana OPS, Asawa GL and Pillai ASN (1983) Rational assessment of blockage effect in channel flow past smooth circular cylinders. Journal of Hydraulic Research 21(4): 289-302.

Seckin G (2004) A simple formula for estimating backwater at bridge constrictions. Canadian Journal of Civil Engineering 31(3): 561-568.

Seckin G, Yurtal R and Haktanir T (1998) Contraction and expansion losses through bridge constrictions. Journal of Hydraulic Engineering 124(5): 546-549.

Seckin G, Haktanir T and Knight DW (2007) A simple method for estimating flood flow around bridges. Proceedings of the Institution of Civil Engineers - Water Management 160(4): 195-202, http://dx.doi.org/10.1680/ wama.2007.160.4.195.

Seckin G, Akoz MS, Cobaner M and Haktanir T (2009a) Application of ANN techniques for estimating backwater through bridge constrictions in Mississippi River basin. Advances in Engineering Software 40(10): 1039-1046.

Seckin G, Tefaruk H, Murat C and Zeliha S (2009b) Forecasting backwater through bridge constrictions in Mississippi River basin. River Research \& Applications 25(3): 315-328. Suribabu CR, Sabarish RM, Narasimhan R and Chandhru AR (2011) Backwater rise and drag characteristics of bridge piers under sub-critical flow conditions. European Water 36: $27-35$.

Wang H, Tang HW, Xiao JF, Wang Y and Jiang S (2016a) Clear-water local scouring around three piers in a tandem arrangement. Science China Technological Sciences 59(6): 888-896.

Wang H, Tang H, Liu Q and Wang Y (2016b) Local scouring around twin bridge piers in open-channel flows. Journal of Hydraulic Engineering: 06016008, http://dx.doi.org/ 10.1061/(ASCE)HY.1943-7900.0001154.

Yarnell DL (1934) Bridge Piers as Channel Obstructions. US Department of Agriculture, Washington, DC, USA.

\section{HOW CAN YOU CONTRIBUTE?}

To discuss this paper, please email up to 500 words to the editor at journals@ice.org.uk. Your contribution will be forwarded to the author(s) for a reply and, if considered appropriate by the editorial board, it will be published as discussion in a future issue of the journal.

Proceedings journals rely entirely on contributions from the civil engineering profession (and allied disciplines). Information about how to submit your paper online is available at www.icevirtuallibrary.com/page/authors, where you will also find detailed author guidelines. 